J. Clin. Chem. Clin. Biochem.

Vol. 14, 1976, pp. 53-57

\title{
Influence of Auxiliary Enzymes on the Spectrophotometric Measurement of Alanine Aminotrans- ferase and Aspartate Aminotransferase Activities
}

\author{
By K. Jung, Christa Fechner and E. Egger \\ Department of Clinical Biochemistry, Charitè, Humboldt University Berlin
}

(Eingegangen am 11. Juli/30. September 1975)

\begin{abstract}
Summary: We investigated the enzyme activity of the blank in the spectrophotometric determination of alanine aminotransferase activities and aspartate aminotransferase activity. 6 lactate dehydrogenase and 3 malate dehydrogenase preparations from different manufacturers and from different organs showed additional and contaminating activity. The additional activity depends upon the 2-oxoglutarate concentration. The contaminating activity is caused by alanine aminotransferase and aspartate aminotransferase in the auxiliary enzymes. We propose that exact definitions must be given for the auxiliary enzymes in the recommendations of standard determinations for enzyme activities.
\end{abstract}

\section{Einfluß der Hilfsenzyme auf die spektrophotometrische Bestimmung der Aktivität von Alanin- und Aspartatamino- transferase}

Zusammenfassung: 6 Lactatdehydrogenase- und 3 Malatdehydrogenase-Präparate verschiedener Hersteller und unterschiedlicher Organherkunft wurden hinsichtlich der Leerwert-Aktivität bei der Alanin- bzw. Aspartataminotransferase-Aktivitätsbestimmung mit dem UV-Test untersucht. Sie zeigten unterschiedlich hohe Neben- und Fremdaktivitätsanteile. Die Nebenaktivität war von der 2-Oxoglutarat-Konzentration abhängig. Die Fremdaktivität war in erster Linie durch die in den Hilfsenzymen enthaltene Alanin- und Aspartataminotransferase bedingt. Es wird gefordert, für Standardvorschriften von Enzymaktivitätsbestimmungen die Qualität der Hilfsenzyme exakt zu definieren.

In determinations of alanine aminotransferase ( $L$-alanine: 2-oxoglutarate aminotransferase, EC 2.6.1.2) and aspartate aminotransferase ( $\dot{L}$-aspartate: 2-oxoglutarate aminotransferase, EC 2.6.1.1) activities the spectrophotometric methods have important advantages over colorimetric procedures. Exxamining the influence of temperature and other reaction conditions on the measurements of alanine aminotransferase and aspartate aminotransferäse activities by the coupled kinetic method we have observed that the sort of auxiliary enzymes used is very important $(1,2)$. Recently standard conditions for the estimation of enzyme activity were presented (3-6). In these recommendations exact data for the concentration of auxiliary enzymes were given, but nothing was said on the quality of auxiliary enzymes. The aim of this study is to show that it is also necessary to give precise data for the quality of auxiliary enzymes used in spectrophotometric methods for estimation of aminotransferase activities.

\section{Methods and mạterials}

Kinetic measurement of enzyme reaction velocity was performed at $37^{\circ} \mathrm{C}$ on an LKB Reaction Rate Analyzer 8600 . Unless otherwise stated the final concentrations in the test mixture were $100 \mathrm{mmol} / 1 \mathrm{Tris} / \mathrm{HCl}$ buffer $\mathrm{pH} 7.4,200 \mathrm{mmol} / \mathrm{l} L$-aspartate or $400 \mathrm{mmol} / 1 L$-alanine, $0.18 \mathrm{mmol} / 1 \mathrm{NADH}$ and $12 \mathrm{mmol} / 1$ 2-oxoglutarate. The reaction mixture for determination of alanine aminotransferase activity contained, per liter, $2000 \mathrm{U}$ lactate dehydrogenase ( $L$-lactate: NAD oxidoreductase, EC 1.1.1.27), for determination of aspartate aminotransferase activity $1000 \mathrm{U}$ malate dehydrogenase ( $L$-malate: NAD oxidoreductase, EC 1.1.1.37). In incubations with pyridoxal-5'-phosphate the coenzyme was added in the concentration of $200 \mu \mathrm{mol} / \mathrm{l}$. The reaction was started by addition of 2-oxoglutarate. The total volume was $1.5 \mathrm{ml}$ including $0.2 \mathrm{ml}$ water in place of serum to achieve the same conditions as for the assay in routine analysis. The activities were measured by continuous monitoring of the reaction rate for 5 minutes. Therefore, the rate of this change per minute if multiplied by the factor 1206 gives the apparent aminotransferase activity in U/1. Duplicate assays were performed and the data given are the means of the duplicates. The standard deviation was estimated by duplicates using the following equation $s=\sqrt{\frac{R^{2}}{2 m}}(R=$ difference between duplicates, $m=$ number of 
Tab. 1. Investigated preparations of lactate dehydrogenase and malate dehydrogenase

\begin{tabular}{|c|c|c|c|}
\hline Enzyme preparation & Origin & Firm & Activity (U/mg) \\
\hline malate dehydrogenase & $\begin{array}{ll}1 & \text { bovine heart } \\
2 & \text { bovine heart } \\
3 & \text { bovine heart } \\
4 & \text { rabbit heart, band } 1 \\
5 & \text { rabbit muscle } \\
6 & \text { pig muscle, band } 5 \\
1 & \text { pig heart } \\
2 & \text { pig heart } \\
3 & \text { pig heart }\end{array}$ & $\begin{array}{l}\text { Boehringer } \\
\text { Worthington } \\
\text { AW Dresden } \\
\text { Boehringer } \\
\text { Boehringer } \\
\text { Boehringer } \\
\text { Boehringer } \\
\text { Worthington } \\
\text { AW Dresden }\end{array}$ & $\begin{array}{r}121 \\
265 \\
585 \\
158 \\
567 \\
220 \\
85 \\
117 \\
35\end{array}$ \\
\hline
\end{tabular}

duplicate assays). $s$ was $\pm 0.13 \mathrm{U} / 1$ in the range of apparent aminotransferase activities from 0.9 to $5.2 \mathrm{U} / 1$.

The preparations of lactate dehydrogenase and malate dehydrogenase are listed in table 1 . The enzymes were suspended in saturated ammonium sulfate solution. Lactate dehydrogenase and malate dehydrogenase were assayed on an Eppendorf photometer at $334 \mathrm{~nm}$ and $25^{\circ} \mathrm{C}$. These assays were necessary because the lactate dehydrogenase and malate dehydrogenase from the manufacturers were tested by different methods.

$L$-aspartic acid, $L$-alanine, 2-oxoglutaric acid, pyridoxal- 5 -phosphate, NADH, sodium pyruvate and Tris were obtained from Boehringer Corp., Mannheim, oxalacetic acid from Reanal, Budapest. All other chemicals were of the highest purity available from commercial sources.

\section{Results}

A source of error in the spectrophotometric measurement of aminotransferase activities is due to spontaneous decomposition of $\mathrm{NADH}$ in the reaction mixture. This spontaneous decomposition was measured over a time of 15 minutes. The apparent enzyme activity was of small range (tab. 2). In further experiments the spontaneous decomposition of $\mathrm{NADH}$ was taken into consideration.

The reaction mixture containing only water in place of serum showed an apparent aminotransferase activity with all lactate dehydrogenase and malate dehydrogenase preparations used as auxiliary enzymes. It was found necessary to add 2-oxoglutarate for yielding this blank activity. Omitting 2-oxoglutarate from the reaction mixture the observed activities do not exceed the activities listed in table 2 . The source of error in the measurement of aminotransferase activities could lie in an impurity of auxiliary enzymes, for example a contamination

Tab. 2. Spontaneous decomposition of NADH in the reagent. All reagents contain $0.18 \mathrm{mmol} / 1 \mathrm{NADH}$ but not 2 -oxoglutarate

\begin{tabular}{ll}
\hline Reagent & $\begin{array}{l}\text { apparent activity } \\
\text { (U/1) }\end{array}$ \\
\hline Tris buffer & 0.09 \\
phosphate buffer & 0.39 \\
Tris + aspartate & 0.23 \\
Tris + alanine & 0.25 \\
phosphate + aspartate & 0.41 \\
phosphate + alanine & 0.34 \\
\hline
\end{tabular}

with glutamate dehydrogenase ( $L$-glutamate: $\mathrm{NAD}(\mathrm{P})$ oxidoreductase, deaminating, EC 1.4.1.3) or with aminotransferase. These activities are referred to as "contaminating activities". Another possible cause of this blank activity is the reaction of lactate dehydrogenase and malate dehydrogenase with 2-oxoglutarate. In the following this will be called "additional activity". In our experiments we have attempted to differentiate these sources of blank activity.

Studies on the relationship between apparent activity and the concentration of 2-oxoglutarate are shown in figures 1 and 2 . Under these conditions the activity depends upon the concentration of 2-oxoglutarate, especially for the malate dehydrogenase preparations 1 and 2 and lactate dehydrogenase preparations 3 and 4 . It is noteworthy that every preparation of lactate dehydrogenase and malate dehydrogenase yielded a 2-oxoglutarate activity as additional activity.

In subsequent experiments we measured the contaminating activities by increasing the amino acid concentration. As shown in figure 3, lactate dehydrogenase

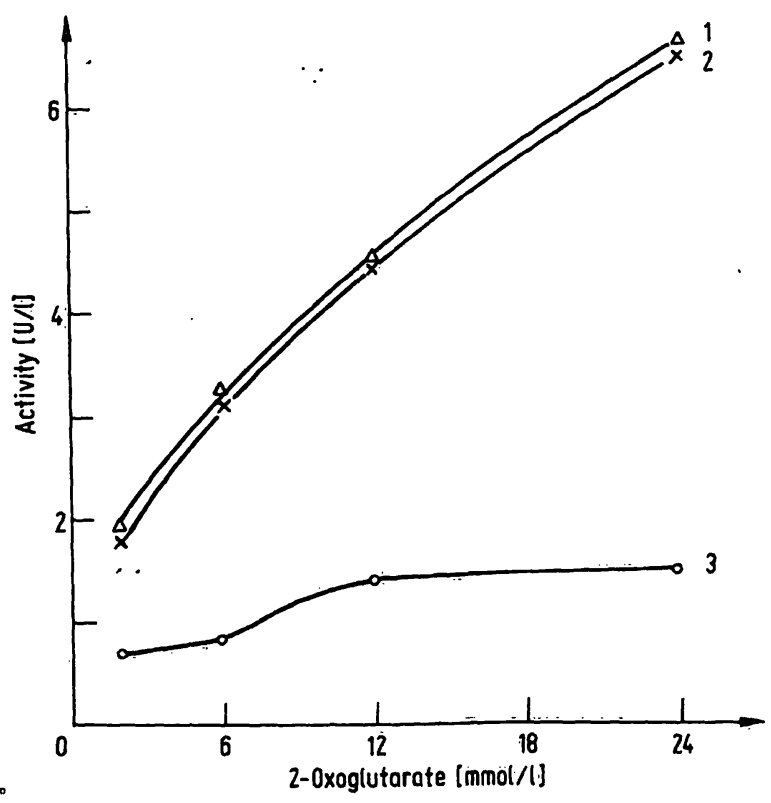

Fig. 1. Apparent aspartate aminotransferase activity caused by the additional activity of malate dehydrogenase preparations (cf. tab. 1) with 2-oxoglutarate as substrate. 


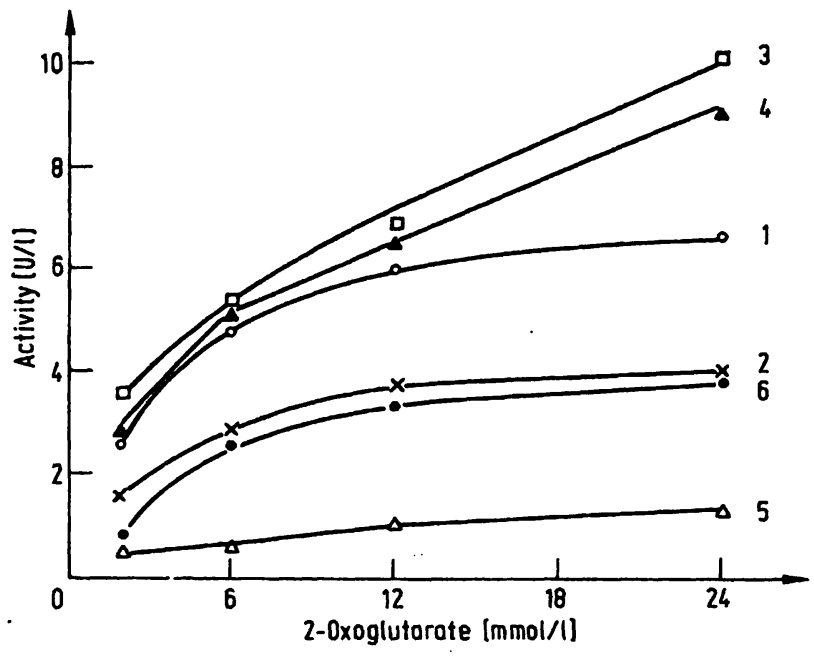

Fig. 2. Apparent alanine aminotransferase activity caused by the additional activity of different lactate dehydrogenase preparations (cf. tab. 1) with 2-oxoglutarate as substrate.

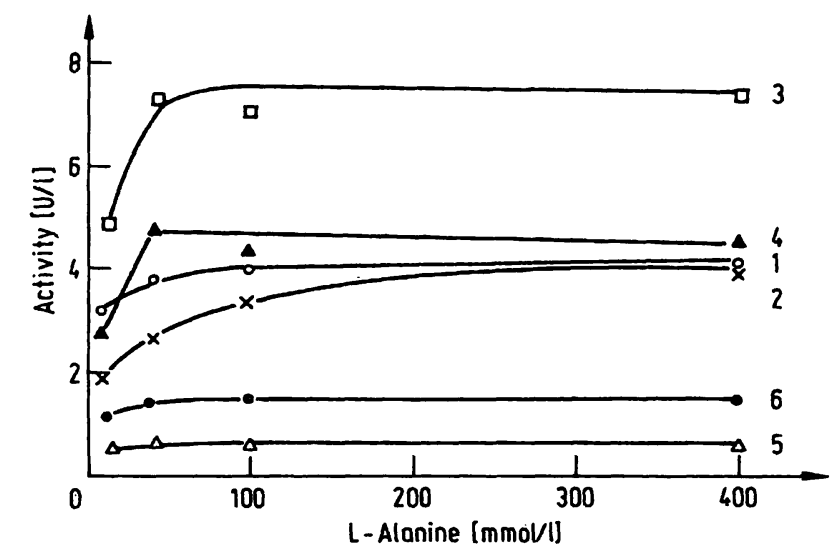

Fig. 3. Apparent alanine aminotransferasc activity caused by the contaminating activity of different lactate dehydrogenase preparations (cf. tab. 1 ) in dependence on the $L$-alanine concentration.

preparations 1 to 4 showed an increase in activity with increasing concentrations of alanine. Little effect could be found in lactate dehydrogenase preparations 5 and 6 . When the dependence of activity on the concentration of aspartate was examined, the three preparations were found to behave differently (fig. 4). The malate dehydrogenase preparation 1 showed a saturation by low concentrations of aspartate. The malate dehydrogenase preparation 2 was also saturated by low concentrations of aspartate and it showed an inhibition by $200 \mathrm{mmol} / \mathrm{l}$ aspartate. On the other hand, preparation 3 is remarkably stimulated in relation to the concentration of aspartate.

Another series of experiments was undertaken to test the influence of $\left(\mathrm{NH}_{4}\right)_{2} \mathrm{SO}_{4}$. As shown in table 3, increasing concentrations of $\left(\mathrm{NH}_{4}\right)_{2} \mathrm{SO}_{4}$ do not influence the activity of apparent alanine aminotransferase for lactate dehydrogenase preparations, with the exception of lactate dehydrogenase preparation 3. Experiments with malate dehydrogenase preparations show an inhibitory effect

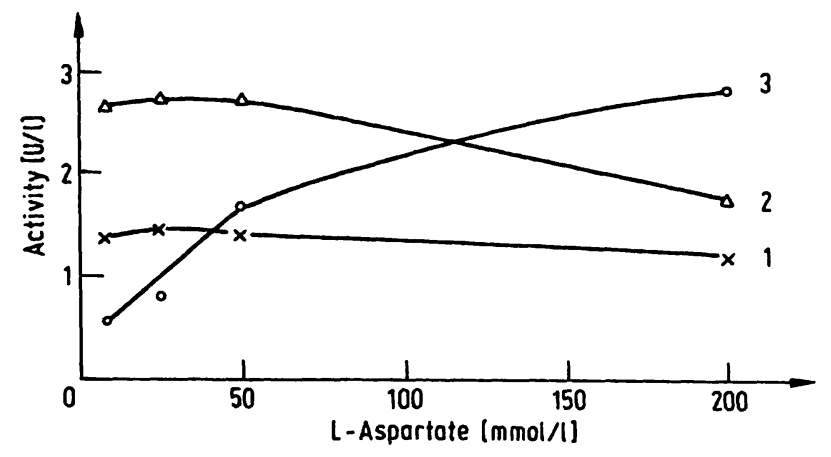

Fig. 4. Apparent aspartate aminotransferase activity caused by the contaminating activity of different malate dehydrogenase preparations (cf. tab. 1) in dependence on the $L$-aspartatc concentration.

Tab. 3. Influence of $\left(\mathrm{NH}_{4}\right)_{2} \mathrm{SO}_{4}$ on the blank activity All preparations used were dialysed. The observed blank activity was assigned a value of 1 in the reaction mixture without $\left(\mathrm{NH}_{4}\right)_{2} \mathrm{SO}_{4}$. Concentrations were listed as $\mathrm{mmol} / \mathrm{l}, \mathrm{pH}$ was adjusted to $\mathrm{pH} 7.4$.

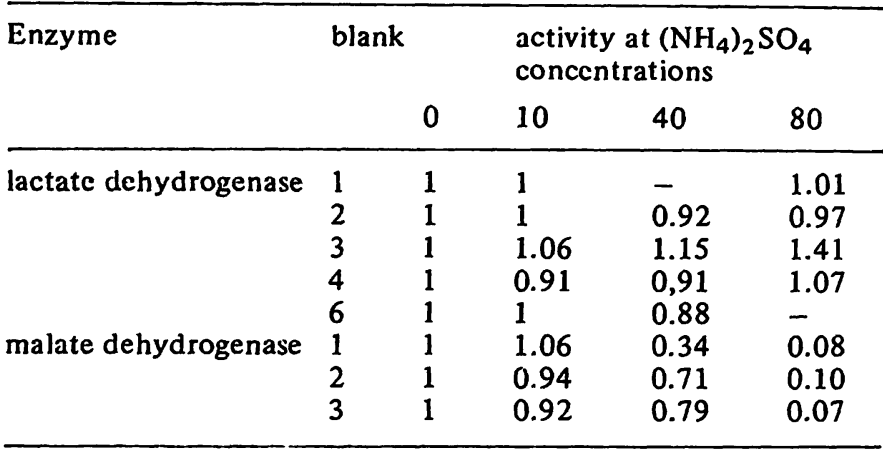

Tab. 4. Stimulation of apo-aminotransferase activities in lactate dehydrogenase and malate dehydrogenase preparations by addition of pyridoxal-5'-phosphate

Apparent aminotransferase activity of lactate dehydrogenase and malate dehydrogenase preparations was measured in the aminotransferase reaction mixturc with and without pyridoxal-5'-phosphate. The stimulation of activity by addition of pyridoxal-5'-phosphate is listed as the factor of stimulation

\begin{tabular}{llcl}
\hline Enzyme & \multicolumn{3}{l}{$\begin{array}{l}\text { Factor of stimulation by } \\
\text { 200 } \mu \mathrm{mol} / 1\end{array}$} \\
& $\begin{array}{l}\text { pyridoxal-5'- } \\
\text { phosphate }\end{array}$ & $12 \mathrm{nmol} / \mathrm{l}$ \\
\hline malate dehydrogenase & 1 & 6.8 & 1 \\
& 2 & 15.8 & 1.1 \\
lactate dehydrogenase & 3 & 8.0 & 1.1 \\
& 1 & 1.5 & - \\
& 2 & 1.4 & - \\
& 3 & 1.4 & - \\
& 4 & 1.4 & - \\
\hline
\end{tabular}

of $\left(\mathrm{NH}_{4}\right)_{2} \mathrm{SO}_{4}$. We interpret the results in the following way: the apparent aminotransferase activity was not produced by a glutamate dehydrogenase contamination, except in lactate dehydrogenase preparation 3. 
In further experiments we investigated the behaviour of lactate dehydrogenase and malate dehydrogenase preparations in the aminotransferase reaction mixture under the influence of pyridoxal-5'-phosphate (tab. 4). Pyrido$x a l-5$-phosphate reacts with the apo-aminotransferase in malate dehydrogenase and lactate dehydrogenase preparations. Therefore, a stimulation of apparent activity is observed. As seen in table 4 the malate dehydrogenase preparation 1,2, and 3 especially show a very high affinity for pyridoxal-5'-phosphate and a stimulation by this coenzyme. A little stimulation is already observed at concentrations of $12 \mathrm{nmol} / 1$ pyridoxal- $5^{\prime}$-phosphate. Estimating the aspartate aminotransferase activity of sera by kinetic methods as there common practice in clinical chemistry, the pyridostal-5'-phosphate content of serum is high enough, to give this concentration in the reaction mixture.

\section{Discussion}

This investigation was carried in view of the introduction of standardized methods for the estimation of enzyme activities in the clinical chemistry practice in many countries. All publications $(3,4,5)$ recommend methods that use optimal concentrations of substrates, cofactors, and buffers. The methods cited for measuring alanine aminotransferase and aspartate aminotransferase activity do not include detailed recommendations for the quality of indicator enzymes $(3,4,5)$. It is surprising that the influence of auxiliary enzymes on the spectrophotometric measurement of alanine aminotransferase and aspartate aminotransferase activities has received little consideration hitherto $(8,9)$. There are many possibilities of error in measuring the aminotransferase activities with the UV-test. One of these is the reagent blank activity we have observed in all lactate dehydrogenase and malate dehydrogenase preparations. This reagent blank activity is the sum of additional activity and the contaminating activity and is much too high compared with the reference values. The upper limit of the normal range of aspartate aminotransferase activity is $35 \mathrm{U} / 1$ and of alanine aminotransferase activity $33 \mathrm{U} / \mathrm{l}$ in females and $49 \mathrm{U} / 1$ in males (10).

It is possible to separate both activities from each other by different reaction mixtures (additional activity: reaction only with 2-oxoglutarate; contaminating activity: the activity in complete reagent mixture minus additional activity). With respect to the first activity, it should be noted that both enzymes - lactate dehydrogenase and malate dehydrogenase - react with 2-oxoglutarate (11, 12). Therefore, lactate dehydrogenase and malate dehydrogenase preparations also show activity for the conversion of the 2-oxoglutarate in addition to their own substrates pyruvate and oxalacetate. This activity increased when the 2-oxoglutarate concentration was increased. In contrast to our results Lott et al. (9) did not find a blank activity when alanine was omitted from the reagent mixture for measuring alanine aminotransferase activity.
Comparing the additional activities of lactate dehydrogenase preparations, we can see that the additional activity of lactate dehydrogenase from heart exceeds the additional activity of lactate dehydrogenase from the muscle. After we had terminated our experiments Chang \& Chung (8) published their studies. They also found higher hydroxyglutarate dehydrogenase activities from heart than from muscle and suggested that the pattern of lactate dehydrogenase isoenzymes in any particular sample affects significantly the determination of alanine aminotransferase activity. Further we found different properties in preparations of the same origin (heart, muscle) but from different manufacturers. It seem to be important that the technology of production of auxiliary enzymes influences the additional activity of auxiliary enzymes. This conclusion is especially confirmed by measuring the additional activity of malate dehydrogenase preparations in the spectrophotometric assay of aspartate aminotransferase activity. All three preparations were taken from bovine heart but the additional activities vary significantly (fig. 1).

The additional activity is an inherent problem of all coupled enzymatic determinations using lactate dehydrogenase and malate dehydrogenase as auxiliary enzymes and 2-oxoglutarate as substrate. Recently, a recommendation of standardized methods for measurements (13) proposes the addition of lactate dehydrogenase for the determination of glutamate dehydrogenase in serum. With this addition of lactate dehydrogenase the preincubation time can been shortened, but the additional activity of lactate dehydrogenase with 2-oxoglutarate must taken into consideration. There is a definite possibility of a significant error because normal values for glutamate dehydrogenase activity do not exceed 3-4 U/l (14).

Contaminating activities must also be taken into account as a further source of error. We did not find glutamate dehydrogenase activity except in lactate dehydrogenase preparation 3 . The results obtained by varying the alanine and aspartate concentrations show that the activity of aminotransferase in lactate dehydrogenase and malate dehydrogenase preparations behaves similarly to alanine aminotransferase and aspartate aminotransferase in serum $(1,2)$. In the recommendations for the standardization of enzyme activity measurements $(3,4,5)$ we lack the exact data for blank activity of reagent mixtures. In the future it should be possible to produce the auxiliary enzymes in a more pure form and to diminish the proportion of contaminating alanine aminotransferase and aspartate aminotransferase activity in lactate dehydrogenase and malate dehydrogenase preparations. Even then the problem remains of additional activity with 2-oxoglutarate. We propose that blank determinations should be performed and the value of the blank activity subtracted from the total activity of the serum activity determinations. We think that the problem can be solved in this way and that this procedure should be included in the recommendations. 
Recommendations for standardization of aminotransferase activity measurements $(3,4,5)$ do not take into consideration the presence of pyridoxal-5'-phosphate in the reagent mixture. The reference method of IFCC for aspartate aminotransferase activity measurement (15) includes the addition of $100 \mu \mathrm{mol} / \mathrm{l}$ pyridoxal-5'-phosphate. This is of great interest because all malate dehydrogenase preparations contained a very large amount of apo-aspartate aminotransferase, as shown by the measurement of the blank activity with pyridoxal-5'-phosphate in the reaction mixture (tab. 4). The apo-alanine amino- transferase activity in lactate dehydrogenase preparations was small. For normal use, the concentrations of pyridoxal-5'-phosphate lies at about $12 \mathrm{nmol} / 1$ in the reaction mixture because the level of pyridoxal- 5 '-phosphate in the serum is $90 \mathrm{nmol} / \mathrm{l}(16) .12 \mathrm{nmol} / 1$ pyridoxal-5'. phosphate stimulates apo-aspartate aminotransferase activity over a small range.

Our studies indicate that it is necessary for a standard recommendation of enzyme activity measurement to define the quality of auxiliary enzymes and to place the problem of blank activity on a sound basis.

\section{References}

1. Lüdtke, B., Jung, K. \& Egger, E. (1975), Acta Biol. Med. Germ. 34, 1339-1346.

2. Lüdtke, B., Jung, K. \& Egger, E. (1975), Rev. Roum. Biochim., in press.

3. Empfehlungen der Deutschen Gesellschaft für Klinische Chemie (1972), this J. 10, 182-192.

4. Wilkinson, J. H., Baron, D. N., Moss, D. W. \& Walker, P. G. (1972), J. Clin. Pathol. 25, 940-944.

5. Committee on Enzymes of the Scandinavian Society for Clinical Chemistry and Clinical Physiology (1974), Scand. J. Clin. Lab. Invest. 33, 291-306.

6. Mitteilungen des Fachausschusses Diagnostische Laboratoriumsmethoden der Deutschen Arzneibuchkommission (1973), Zbl. Pharm. 112, 259-265.

7. Biochemica Katalog C. F. Boehringer, Mannheim 1970.

8. Chang, M. M. \& Chung, T. W. (1975), Clin. Chem. 21, 330-333.
9. Lott, J. A., Turner, K. \& Garafola, E. (1974), Clin. Chem. $20,723$.

10. DAB 7 der DDR-Diagnostische Laboratoriumsmethoden (1968), Akademie-Verlag, Berlin, Lieferung 1972.

11. Meister, A. (1950), J. Biol. Chem. 184, 117-129.

12. Kun, E. (1963), in The Enzymes (Boyer, P. D., Lardy, H. \& Myrbäck, K., eds.) 2nd. ed., p. 149-160, Academic Press, New York.

13. Empfehlungen der Deutschen Gesellschaft für Klinische Chemie (1974), this J. 12, 391.

14. Schlebusch, H., Rick, W. \& Knedel, W. (1974), this J. 12, 52.

15. IFCC Enzyme Method, Draft proposal No. 6 of Aspartate Aminotransferase (1975).

16. Henry, R. J. (1964), Clinical Chemistry: Principles and Technics, p. 723, Hoeber, New York.

Dr. K. Jung, Ing. Christa Fechner, Prof. Dr. E. Egger, Abteilung Klinische Biochemie des Bereichs Medizin (Charité) und Lehrstuhl Pathologische Biochemie der Humboldt-Universität zu Berlin, 104 Berlin, Schumannstr. 20/21. 
